\title{
Avaliação epidemiológica, clínica, anatomopatológica e etiológica de surtos de ataxia em cabritos e cordeiros
}

\author{
Epidemiological, clinical, etiological and histopatological evaluation of delayed enzootic ataxia \\ outbreaks in kids and lambs
}

\author{
Néria Vania Marcos dos Santos ${ }^{1}$ Jorge Eduardo de Souza Sarkis ${ }^{2}$ José Luiz Guerra $^{3}$ \\ Paulo Cesar Maiorka ${ }^{3}$ Marcos Antonio Hortelani ${ }^{4}$ Francisco Feliciano da Silva $^{5}$ \\ Enrico Lippi Ortolani ${ }^{6}$
}

\section{RESUMO}

Nos anos de 2001 e 2002, 46 cabritos (CAB) e 35 cordeiros (COR) de uma propriedade do agreste do Estado de Pernambuco foram acometidos por ataxia enzoótica (AE) de forma tardia. Houve aumento da incidencia do 1 o ano (46,3\% - CAB; 24,2\% COR) para o ano subseqüente (100\% - CAB e COR). Somente no ano de 2001, houve maior incidência em $C A B(P<0,002)$ que nos COR. Todos os animais acometidos sucumbiram, com exceção de um CAB e um de COR. O quadro clínico variou de acordo com a idade em que surgiram os sintomas, ou seja, de 30 a 45 dias os animais manifestaram paralisia dos membros anteriores e posteriores, acompanhada de espasticidade muscular e morte; com mais de 45 dias, ocorreu paralisia flácida ou espástica apenas dos membros posteriores e morte; somente os cabritos com menos de 45 dias apresentaram movimentos verticais de cabeça. As lesões histopatológicas evidenciadas foram: degeneração axonal, esferóides, gliose e dismielinização no segmento ventral e lateral da medula espinhal. Nos animais com menos de 45 dias, essas lesões foram evidentes na região cervical e nos animas mais velhos na região lombar. Apenas nos cabritos foi constatada lesão degenerativa no cerebelo. A dieta oferecida ao rebanho continha quantidades adequadas de cobre, porém os animais acometidos por AE apresentaram baixos teores de cobre no fígado (45,8mg $\left.\mathrm{kg}^{-1} \mathrm{MS}\right)$. Os elementos antagonizantes do cobre, Mo, S, e Zn, estavam normais, com exceção do ferro, que estava em alta concentração tanto no solo (8600mg $\mathrm{kg}^{-1}$ ) quanto nos alimentos (284 $\left.\mathrm{mg} \mathrm{kg}^{-1}\right)$. $O$ excesso de ingestão de ferro sugere ter provocado a carência de cobre nos animais.

Palavras-chave: ataxia enzoótica, deficiência de cobre, doenças de cabritos e cordeiros.

\section{ABSTRACT}

An outbreak in 46 kids and 36 lambs with delayed enzootic ataxia (EA) raised in a single farm in the State of Pernambuco, Brazil, in 2001 and 2002 was described. The incidence was lower in 2001 (46.3\% in kids and 24.2\% in lambs) than in 2002 (100\% in both species); only in 2001 the incidence was higher in kids $(\mathrm{P}<0.002)$. All newborns with EA died, but one lamb and one kid. The clinical case was different according to the age of onset of EA. The animals between 30 and 45d old showed both fore and hindlimbs paralysis with muscular spasticity, followed by death. Animals older than 45d had only hindlimbs spasticity or flaccid paralysis followed by death. Only the under 45 days old kids presented head nodding. Axonal degeneration, spheroids, gliosis, and demyelination in the ventral lateral horns of the spinal cord were detected. Newborns less than $45 d$ old had those lesions mainly in the cervical region, while the older in the lumbar region; only the kids had cerebellar lesions. The available diet to the herd had adequate levels of copper, but the liver copper concentration was low in animal with EA (45.8 $\mathrm{mg} \mathrm{kg}^{-1}$ D.M.); the antagonizing elements to the copper (molybdenum, sulfur and zinc) were normal, but the iron levels either in soil $(8,600 \mathrm{mg}$ $\mathrm{kg}^{-1}$ ) and feedstuffs (284mg $\mathrm{kg}^{-1}$ ) were high. Excessive dietary intake of iron might have caused the copper deficiency in the newborns.

Key words: enzootic ataxia, copper deficiency, kids and lambs disease.

\footnotetext{
${ }^{1}$ Departamento de Clínica Médica Veterinária (VCM), Programa de Clínica Veterinária, Faculdade de Medicina Veterinária e Zootecnia (FMVZ) da Universidade de São Paulo (USP), São Paulo, SP, Brasil. E-mail: neria@usp.br.

${ }^{2}$ Centro de Química e Meio Ambiente (CQMA)/Instituto de Pesquisas Energéticas e Nucleares (IPEN), São Paulo, São Paulo, Brasil ${ }^{3}$ Departamento de Patologia Veterinária (VPT), FMVZ/USP, São Paulo, SP, Brasil.

${ }^{4}$ CQMA/IPEN, São Paulo, SP, Brasil.

${ }^{5}$ Departamento de Medicina Veterinária (DMV)/Universidade Federal Rural de Pernambuco UFRP), Recife, Pernambuco, Brasil

${ }^{6}$ VCM/FMVZ/USP. Av, Prof. Orlando M. Paiva, 87, Cidade Universitária, 05508-000, São Paulo, SP, Brasil. E-mail: ortolani@usp.br . Autor para correspondência.
} 


\section{INTRODUÇÃO}

A ataxia enzoótica (AE) é expressão máxima da carência de cobre em cordeiros (COR) e cabritos (CAB) até 180 dias de vida, sendo caracterizada pela dismielinização do sistema nervoso central e pelos sintomas de cambaleio dos membros posteriores e, em menor grau, dos anteriores, paralisia flácida ou espástica, incapacidade total de locomoção e morte. São descritos dois tipos de AE, baseados no local da lesão e na cronologia do quadro. A forma congênita é marcada pela destruição da substância branca cerebral e acomete neonatos nos primeiros dias de vida e a forma tardia é caracterizada pelas lesões no tronco encefálico e tratos motores da medula espinhal, com ocorrência após a 3ํㅗㄹ semana de vida (UNDERWOOD \& SUTTLE, 1999).

Nos dois tipos de AE, há depleção de cobre no organismo tanto da fêmea prenhe como dos neonatos, o que acarreta mielinização imperfeita do sistema nervoso do recém-nascido devido à menor atividade da citocromo $\mathrm{C}$ oxidase e da ceramida galactosil transferase e da produção de fosfolípides, importantes na síntese da mielina. O surgimento da AE está ligado com a precocidade do processo carencial e com a cronologia da mielinização no feto, que se inicia no sistema nervoso central no 960 dia de gestação, com máxima atividade ao redor do $20^{\circ}$ dia que antecede o parto; seguido da medula espinhal e nervos periféricos, nos quais a mielina é mais depositada do final da gestação até o $30^{\circ}$ dia posterior ao parto (HOWELL \& GOWTHORNE, 1987).

No Brasil, já foram descritos sucintamente, sem grandes detalhes, quadros de ataxia enzoótica do tipo tardio, apresentando paralisia flácida em COR e CAB criados nos Estados do Piauí e da Paraíba; e do tipo congênito em COR no Rio Grande do Sul (TOKARNIA et al., 1966; RIET-CORREA et al., 2001).

O objetivo do presente trabalho é descrever os aspectos epidemiológicos, etiológicos, clínicos e anatomopatológicos de surtos de ataxia enzoótica da forma tardia que ocorreram em COR e CAB no decorrer de dois anos, numa criação de ovinos e caprinos na região agreste do Estado de Pernambuco.

\section{MATERIAL E MÉTODOS}

A propriedade estava localizada no município de Surubim, região do agreste do Estado de Pernambuco. Os surtos ocorreram, no ano de 2001, num rebanho de 118 caprinos e 145 ovinos e, no ano de 2002, num rebanho de 54 caprinos e 48 ovinos. As cabras eram mestiças de raças nativas com Anglonubiana e as ovelhas de raças nativas com Morada Nova e Santa Inês. Os animais eram criados extensivamente, pastoreando vegetação nativa e suplementados regularmente apenas com sal comum.

Foram realizadas visitas na propriedade nos anos de 2001 e de 2002, detectando-se vários casos de AE em animais jovens. Três animais em 2001 e três em 2002 (quatro CAB e dois COR) foram sacrificados com anestesia profunda, à base de acepromazina e tiopental, e em seguida necropsiados com retirada do sistema nervoso central e do fígado. Amostras do SNC foram acondicionadas em solução de formol neutro e tamponada a $10 \%$ e processadas pelos métodos histopatológicos de rotina e corados pela Hematoxilina-Eosina; amostras da medula espinhal também foram coradas por Luxol Fast Blue após corte por congelação, para avaliar a mielinização. $O$ fígado foi congelado a $-20^{\circ} \mathrm{C}$ para posterior análise dos teores de cobre.

Amostras de sangue $(n=74)$ de animais jovens e adultos foram coletadas da veia jugular em frascos de vacutainer sem anticoagulantes. O soro foi congelado a $-20^{\circ} \mathrm{C}$ para posterior análise dos teores de cobre no soro. As amostras de fígado, foram secas e digeridas em seguida com solução de ácido nítrico e perclórico (SOLAIMAN et al. 2001). As determinações do cobre em todas as amostras foram realizadas por espectrofotômetro de absorção atômica (modeloSpectra AA-220- Fast Seqüencial - Varian ${ }^{\circledR}$ ).

Também foram coletadas amostras de solo da propriedade e dos principais alimentos disponíveis para o rebanho. Em agosto de 2002, foram obtidas quatro amostras de cada uma das três principais plantas que serviam de alimento para o rebanho, ou seja: Hyptis suaveolens (alfazema); Mimosa tenuiflora (jurema) e Jacquemotia densiflora (amarra cachorro). Amostras de solo foram obtidas de dez diferentes pontos da pastagem. Os teores de $\mathrm{Cu}, \mathrm{Fe}, \mathrm{Zn}$ e Mo foram determinados no solo por fluorescência de Raios - X (modelo EDX-900 Shimadzu ${ }^{\circledR}$ ). Nas plantas, as determinações de $\mathrm{Cu}, \mathrm{Fe}$, Zn, e Mo foram realizadas por espectrômetro de massa de dupla focalização de plasma induzido (HR-ICPMS-Finnigan MAT $^{\circledR}$ ). O teor de enxofre nas plantas foi determinado por método turbidimétrico (KRUG et al., 1977).

As taxas de incidência, mortalidade e letalidade da AE foram calculadas segundo fórmulas descritas por SMITH (1991). A comparação da taxa de incidência de AE entre COR e CAB foi feita por meio do teste de qui-quadrado. Já os teores de cobre sérico foram comarados pelos testes $\mathrm{F}$ e comparativo de Duncan (SAMPAIO, 2002). 


\section{RESULTADO}

Histórico e aspectos epidemiológicos, clínicos e histopatológicos

O início da criação ocorreu no ano de 1999, com cabras e ovelhas nulíparas compradas de outras regiões do Estado de Pernambuco, e, neste ano, não houve relato de caso de AE. No ano subseqüente, começaram a surgir casos esporádicos desta enfermidade, mas que não levaram o criador a buscar assistência veterinária. Contudo, no ano de 2001, o número de casos aumentou drasticamente, o que motivou a procura de técnicos especializados para a resolução do problema e a venda de boa parte das cabras e ovelhas para terceiros. No ano de 2002, o rebanho estava reduzido, porém a incidência de AE foi máxima.

Em 2001, o rebanho caprino era constituído por 62 fêmeas, 2 machos e 54 cabritos, sendo que 25 destes últimos foram acometidos por AE; o rebanho ovino era formado por 81 fêmeas, 2 machos e 62 COR, sendo que 15 destes foram acometidos por AE. Em 2002, havia 29 cabras, 1 bode e $24 \mathrm{CAB}$, sendo que todos os $\mathrm{CAB}$ foram acometidos por AE; o rebanho ovino era constituído por 27 ovelhas, 1 carneiro e 20 COR, sendo que todos os COR foram acometidos por AE. A incidência e a letalidade foram máximas em 2002, enquanto que em 2001 sobreviveram um COR e um CAB. Na tabela 1, estão especificados os resultados referentes às taxas de incidência e letalidade em $2001 \mathrm{e}$ 2002 em CAB e COR, ressaltando-se nos dados gerais que quando comparados aos cordeiros, maior número de cabritos foram acometidos $(\mathrm{P}<0,002)$.

Os animais nasciam normais e saudáveis e, a partir de 30 até 120 dias de idade, desenvolviam o quadro de AE. Nos cabritos e cordeiros com mais de 45 dias de idade, a evolução clínica era mais prolongada, caracterizada por ataxia apenas dos membros posteriores. Na maioria destes animais, surgia o quadro sintomatológico de incoordenação dos membros posteriores, de quedas freqüentes e de dificuldade para se manter em estação. Mesmo assim, alguns destes deslocavam-se para mamar, com os membros anteriores flexionados, andando ajoelhados e, ocasionalmente, posicionavam-se em atitude de "cão sentado". A avaliação do reflexo sensitivo na região interdigital dos membros posteriores revelou diminuição da resposta sensitiva e motora. Não foram constatadas alterações no exame das grandes funções (batimento cardíaco, freqüência respiratória e temperatura retal). O apetite e a consciência eram mantidos, assim como o reflexo de sucção da mamada e a capacidade de deglutição. Alguns animais, se levantados, conseguiam dar poucos passos, caindo em seguida. A partir de 15 dias de decúbito, os animais haviam emagrecido e, dependendo da incapacidade locomotora, sucumbiam por inanição. Caso fossem alimentados artificialmente, permaneciam vivos e conscientes por até 30 dias. No decorrer desse tempo, muitos neonatos apresentaram quadros inflamatórios, tais como conjuntivite catarral bilateral, discreto quadro pulmonar acompanhado de tosse e secreção nasal catarral, lesões de ectima contagioso e diarréia discreta. Alguns animais também manifestaram ranger de dentes, principalmente ao término do quadro.

Nos animais com idade entre 30 e 45 dias, desenvolvia-se inicialmente ataxia dos membros posteriores e, após alguns dias, paralisia dos anteriores, a qual antecedia o surgimento de espasticidade permanente de todos os membros (Figura 1), leves tremores cutâneos e ranger de dentes. Nos CAB dessa idade, também foram observados os movimentos verticais de cabeça. A falta de mobilidade provocava quase que invariavelmente escaras de decúbito e meteorismo gasoso, que precediam a morte em geral entre 15 a 20 dias após o surgimento dos primeiros sintomas. Em nenhum dos animais foi observada a presença dos seguintes sintomas: falta de consciência, amaurose, nistagmo, surdez cortical, diminuição do reflexo pupilar e anemia.

Tabela 1 - Taxas de incidência (\%) e letalidade (\%) da ataxia enzoótica em cabritos e cordeiros de uma propriedade em Surubim - PE, nos anos de 2001 e 2002.

\begin{tabular}{|c|c|c|c|c|c|c|}
\hline \multirow{2}{*}{ Espécie } & \multicolumn{2}{|c|}{2001 (\%) } & \multicolumn{2}{|c|}{2002 (\%) } & \multicolumn{2}{|c|}{ Dados gerais } \\
\hline & Incidência & Letalidade & Incidência & Letalidade & Incidência & Letalidade \\
\hline Caprina & $46,3^{\mathrm{a}}$ & $96,0^{\mathrm{a}}$ & $100^{\mathrm{a}}$ & $100^{\mathrm{a}}$ & $68,7^{\mathrm{a}}$ & $97,8^{\mathrm{a}}$ \\
\hline Ovina & $24,2^{b}$ & $96,3^{\mathrm{a}}$ & $100^{\mathrm{a}}$ & $100^{\mathrm{a}}$ & $42,7^{\mathrm{b}}$ & $97,1^{\mathrm{a}}$ \\
\hline
\end{tabular}

Letras minúsculas distintas nas colunas indicam diferenças significativas entre as espécies $(\mathrm{P}<0,002)$.

Ciência Rural, v.36, n.4, jul-ago, 2006. 


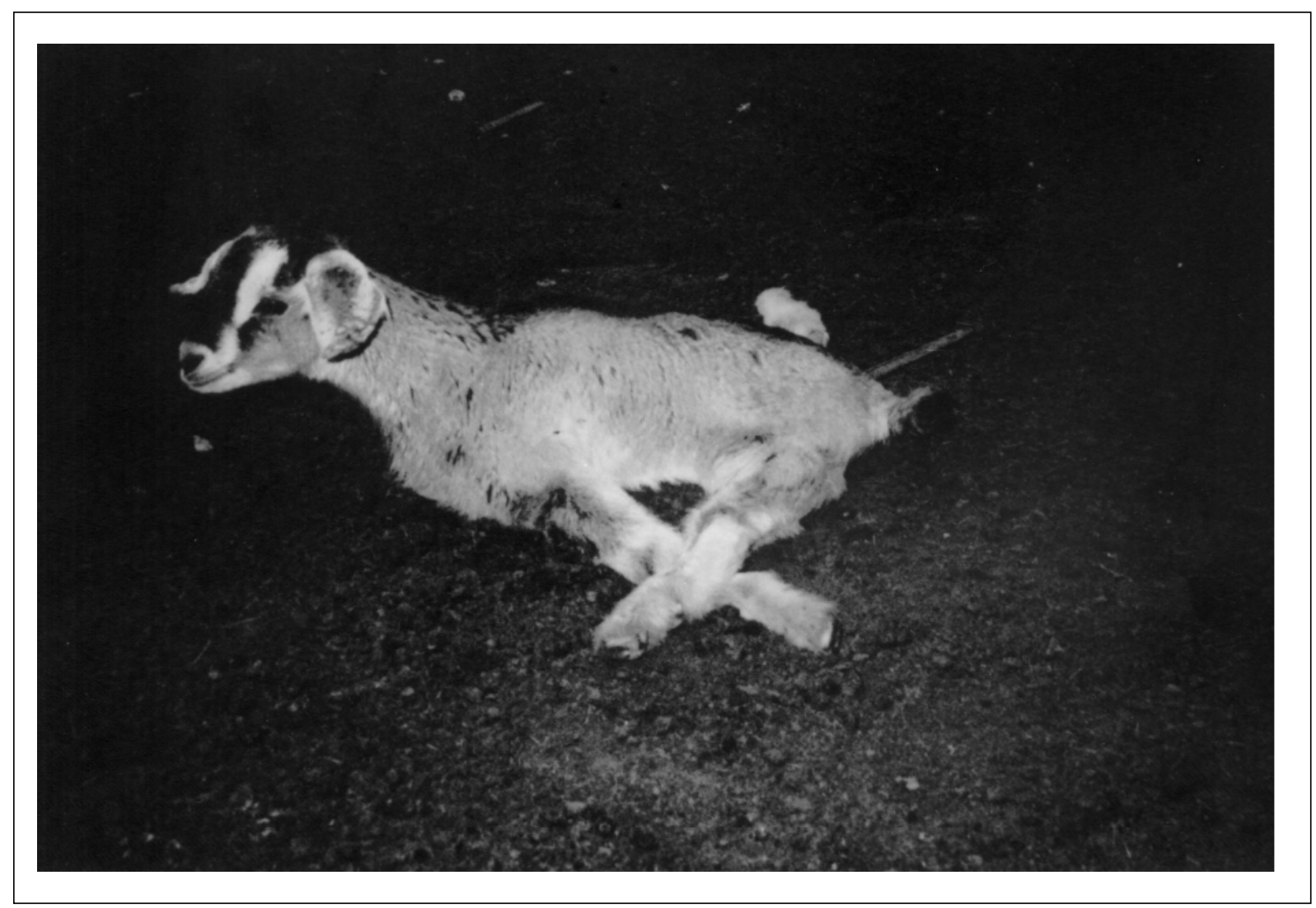

Figura 1 - Cabrito com menos de 45 dias de idade, apresentando quadro clínico severo de ataxia enzoótica, com tetraplegia e espasticidade dos quatro membros e balançar vertical de cabeça.

Dois animais (um CAB e um COR) com quadros brandos de AE sobreviveram no ano de 2001. Os sintomas surgiram após o $90^{\circ}$ dia de vida e se caracterizavam por cambaleio do trem posterior e posição temporária de “cão sentado”. A recuperação foi lenta e gradativa, mas permaneceram seqüelas tornando a locomoção mais dificultosa. Com o emagrecimento dos animais, o criador optou pelo sacrifício.

Não foram encontrados achados patológicos macroscópicos. Mas o exame histopatológico revelou em todos os animais um leve edema e congestão cerebral. Na medula espinhal, detectou-se, pela coloração de HE, degeneração axonal, gliose, esferóides, leve infiltrado mononuclear e manguitos perivasculares. Pela coloração de luxol fast blue, verificou-se nas regiões dos cornos ventrais da medula espinhal áreas de dismielinização, sendo mais evidentes na região cervical dos animais com menos de 45 dias de idade, enquanto que, nos mais velhos, este processo foi mais evidente na porção lombar. Apenas nos cabritos mais jovens foram detectadas lesões no cerebelo, caracterizadas por degeração axonal e vacuolização da substância branca.

Teores de vários elementos em amostras biológicas e do solo

Os teores de cobre sérico em caprinos e ovinos $(n=6)$ acometidos por $\mathrm{AE}\left(12,9 \pm 1,3 \mu \mathrm{m} \mathrm{L}^{-1}\right)$ não foram diferentes $(\mathrm{P}>0,15)$ dos encontrados em animais jovens hígidos $(n=16)(11,3 \pm 2,35)$. Com exceção do ano de 2002, em que os ovinos adultos apresentaram menores concentrações de cobre que os caprinos adultos $(\mathrm{P}<0,03)$, não existiram diferenças entre as comparações realizadas, inclusive com os teores obtidos de CAB e COR acometidos com AE (P > 0,25). As concentrações de $\mathrm{Cu}$ hepático nas duas espécies apresentaram valor de mediana de 45,8mg kg-1 M.S (19,4 a $140 \mathrm{mg} \mathrm{kg}^{-1}$ ). Os teores de $\mathrm{Cu}, \mathrm{S}$, Fe, Mo e Zn das plantas e solo encontram- se na tabela 2.

Ciência Rural, v.36, n.4, jul-ago, 2006. 
Tabela 2 - Teores de Cu, Fe, Mo, e Zn (mg kg-1) e S (\%) nas forragens (Alfazema [AL]; Jurema [JU]; Amarra Cachorro [AC]) e no solo do pasto utilizado pelo rebanho Surubim - PE, agosto de 2002.

\begin{tabular}{|c|c|c|c|c|c|}
\hline Plantas & $\mathrm{Cu} \mathrm{mg} \mathrm{kg}^{-1}$ & S (\%) & Fe mg kg ${ }^{-1}$ & Mo mg kg & Zn mg kg ${ }^{-1}$ \\
\hline AL & 11,3 & 0,15 & 304 & 0,15 & 56,71 \\
\hline JU & 6,97 & 0,15 & 166 & 0,08 & 35,11 \\
\hline $\mathrm{AC}$ & 11,5 & 0,20 & 324 & 0,21 & 50,51 \\
\hline Média & $9,8 \pm 2,1$ & $0,16 \pm 0,03$ & $284 \pm 81$ & $0,15 \pm 0,05$ & $42 \pm 14$ \\
\hline Solo & 3,73 & - & 8,600 & 9,44 & 52,45 \\
\hline
\end{tabular}

\section{DISCUSSÃO}

No Brasil, quadros de AE foram esporadicamente descritos em COR e apenas referidos em CAB (TOKARNIA et al. 1966; RIET-CORREA et al. 2001), relatando sucintamente casos clínicos isolados, enfatizando os achados anatomopatológicos. Já o presente trabalho traz subsídios epidemiológicos, etiológicos e clínicos, que podem contribuir para o melhor entendimento desta enfermidade em nossas condições.

Os dados obtidos indicam que o presente surto trata-se de uma forma de AE tardia. Segundo RADOSTITS et al. (2002), enquanto que a forma congênita se dá apenas em condições em que a carência dietética de cobre em fêmeas prenhes é extrema, na tardia, esta deficiência é bem menos pronunciada, acometendo neonatos mais velhos, a partir de três semanas de vida, idade inferior à observada neste surto. Os teores de cobre séricos nas fêmeas indicam que os valores médios encontraram-se dentre os valores normais.

Em 1998, os animais, na sua maioria fêmeas nulíparas, foram adquiridos de rebanhos em que a AE não era incidente. Presume-se que os teores de cobre hepático estavam adequados, permitindo que os animais nascidos em 1999 não desenvolvessem a carência que teve início apenas no ano de 2000. Pelo histórico, a incidência da enfermidade aumentou, sendo máxima em 2002. Idêntica constatação também já foi descrita anteriormente na literatura (BREWER, 1983).

No ano de 2001, a incidência de AE foi maior em $\mathrm{CAB}(\mathrm{P}<0,002)$ que em cordeiros, atingindo $100 \%$ em ambas as espécies em 2002 (Tabela 1). Não se encontrou na literatura trabalhos que descrevessem surtos de AE em rebanhos conjuntos de ovinos e caprinos, ou estudos comparativos de susceptibilidade entre estas espécies. Embora esta enfermidade seja tradicionalmente descrita em cordeiros, vários são os relatos em cabritos (OWEN et al., 1965; INGLIS et al., 1986; RIET-CORREA et al., 2001; RADOSTITS et al., 2002). Mesmo assim, OWEN et al. (1965) induziram AE em CAB e confrontaram seus dados com outros autores, comparando o estado de cobre em ovelhas e cabras lactantes e em suas crias que tiveram AE. Concluíram que os teores de cobre, tanto sérico quanto hepático, eram menores nos ovinos, indicando que o limiar mínimo para a ocorrência da enfermidade era mais baixo nesta espécie. Esta comparação sugere hipoteticamente uma maior susceptibilidade da espécie caprina. Embora no ano de 2001 não ocorresse diferença nos teores séricos de cobre nos animais adultos $\left(11,7 \mu \mathrm{mol} \mathrm{L}{ }^{-1} \pm 1,6\right)$, no ano subseqüente este foi menor na raça ovina, o que enfatiza a hipótese supracitada. Mesmo assim, outros trabalhos são necessários para confirmar tal suposição.

A taxa de letalidade em ambos os anos estudados foi altíssima, semelhante a outras descrições (BARLOW et al., 1960; OWEN et al., 1965). Embora o tratamento dos animais afetados seja pouco ou nada eficiente, pois as lesões decorrentes da dismielinização são praticamente irreversíveis, a prevenção, dando-se suplementos contendo cobre às fêmeas prenhes, evita o surgimento de novos casos (INGLIS et al., 1986). É interessante relatar que foi sugerido, em 2001, que o proprietário adotasse tal suplementação, o que infelizmente não foi realizado, culminando com a incidência máxima de AE no ano subseqüente.

O quadro clínico relatado neste trabalho foi semelhante ao descrito por outros autores (OWEN et al., 1965; TOKARNIA et al., 1966; RADOSTITS, et al., 2002). Deve-se ressaltar que, enquanto os neonatos que manifestaram a doença com mais de 45 dias de vida apresentaram um quadro de paralisia flácida dos membros posteriores, os que tinham entre 30 a 45 dias exibiram tanto paralisia dos membros posteriores como anteriores, caracterizada por espasticidade. A mielinização no feto ocorre no sentido centrífugo, ou 
seja, do cérebro para a medula espinhal. Enquanto que no cérebro esse processo se encerra próximo ao parto, na medula espinhal só acontecerá ao término do $1^{\circ}$ mês de vida extra-uterina (HOWELL \& GAWTHORNE, 1987). No presente trabalho, os animais mais jovens tiveram processos intensos de dismielinização na região cervical, caracterizada por paralisia espástica de todos os membros. Já nos casos mais tardios, com paralisia apenas dos membros posteriores, as lesões da medula se concentraram nos segmentos a partir do $2^{\underline{a}}$ vértebra torácica. Os movimentos verticais de cabeça, indicativos de alteração de equilíbrio, só foram verificados em alguns CAB com idades entre 30 e 45 dias de vida e são decorrentes de lesões no cerebelo, citadas em CAB com AE (MAYHEW, 1989).

Os animais com AE que sobreviveram por um maior período tiveram quadros infecciosos concomitantes. Essas complicações pactuam com o fato de os animais carentes em cobre apresentarem menor resistência às doenças devido à imunossupressão (UNDERWOOD \& SUTTLE, 1999).

Apenas dois animais sobreviveram ao quadro, apesar de apresentarem seqüelas. Coincidentemente, manifestaram a doença após o $90^{\circ}$ dia de vida. É bem conhecido o fato de que quanto maior for o período entre o nascimento e o início dos sintomas, menor será a severidade da AE (HOWELL \& GAWTHORNE, 1987).

Os teores de cobre hepático foram relativamente baixos (mediana $45,8 \mathrm{mg} \mathrm{kg}^{-1}$ ) e compatíveis com os descritos em recém-nascidos apresentando AE, ou seja, inferiores a $80 \mathrm{mg} \mathrm{kg}^{-1}$ (BARLOW et al., 1960). Embora os teores de cobre séricos nos animais com AE não estivessem abaixo dos valores considerados normais (maiores que 9,4 $\mu \mathrm{mol} \mathrm{L}{ }^{-1}$ ), os teores hepáticos atingiram valores tão baixos quanto $19 \mathrm{mg} \mathrm{kg}^{-1}$, como foi também constatado por BARLOW et al. (1960). Em apenas um dos recémnascidos detectou-se teor de cobre hepático superior alto (140 $\mathrm{mg} \mathrm{kg}^{-1}$ ), porém constatou-se que este animal tinha sido alimentado artificialmente por várias semanas com ração comercial rica em cobre.

Os alimentos disponíveis ao rebanho (Tabela 2) apresentaram os teores médios de cobre $\left(9,8 \mathrm{mg} \mathrm{kg}^{1}\right)$ normais para a espécie (7 a $11 \mathrm{mg} \mathrm{kg}^{-1}$ ). Investigou-se a relação de outros elementos estarem antagonizando a absorção do cobre. O molibdênio é o microelemento antagonista do cobre mais reconhecido, e uma relação Cu:Mo abaixo de 3 já é considerada prejudicial à absorção do cobre; porém, os teores encontrados de molibdênio nos alimentos foram extremamente baixos. As concentrações de enxofre nas forragens estiveram dentro dos valores considerados normais (até 0,3\% da dieta) e diretamente não influíram na disponibilidade do cobre. Quantidades altas de zinco na dieta também podem interferir no metabolismo do cobre, porém os teores de zinco nas forragens também estavam dentro da normalidade (UNDERWOOD \& SUTTLE, 1999).

Por outro lado, tanto as forragens como o solo continham teores médios relativamente altos de ferro, ou seja, $284 \mathrm{mg} \mathrm{kg}^{-1}$ e $8600 \mathrm{mg} \mathrm{kg}^{-1}$, respectivamente. O solo da propriedade era arenoso, apresentava pH 5,2 e comumente recobria, em forma de poeira, as forragens disponíveis para os animais. Associado a isto, nas visitas à propriedade, constatouse que a pastagem era relativamente escassa, fazendo com que os animais pastassem mais rente ao solo, resultando na maior ingestão deste pelos animais. Estima-se que ovinos pastejando em condição árida, como a presente nestes surtos, ingerem cerca de $160 \mathrm{~g}$ solo/dia, o que pode constituir até $25 \%$ do total de matéria seca ingerida (UNDERWOOD \& SUTTLE, 1999). Considerando hipoteticamente que as presentes fêmeas reprodutoras tivessem ingerido $600 \mathrm{~g}$ de matéria seca de forragens e $160 \mathrm{~g}$ de solo, e levando em conta o teor médio disponível de ferro nestes substratos, isso implicaria numa ingestão diária de 561mg de ferro, 15 vezes maior que o requerimento para as espécies (McDOWEEL, 1992). A alta ingestão de ferro pelos ruminantes interfere na absorção do cobre dietético por dois mecanismos, ou seja, aumentando a combinação deste com o sulfeto no rúmen e por meio da adsorção do cobre no trato gastrintestinal, formando um complexo insolúvel, que implica num aumento de eliminação de cobre nas fezes. Ensaios experimentais com ovinos demonstraram que a ingestão diária de $800 \mathrm{mg} \mathrm{kg}^{-1}$ de ferro já poderia provocar grande depleção no estoque de cobre (UNDERWOOD \& SUTTLE, 1999). Recentemente, foi descrita no Rio Grande Sul condição semelhante à sugerida neste presente surto, no qual bovinos adultos, mesmo recebendo dieta normal em cobre, tiveram morte súbita por carência extrema de cobre, ingerindo capins com altos teores de ferro (MARQUES et al., 2003).

Outras enfermidades e infecções nervosas passíveis de diagnóstico diferencial, tais como abscesso e anormalidades congênitas da medula espinhal, listeriose e a forma nervosa da artrite encefalite caprina (CAE), podem ser descartadas por ausência de lesões histopatológicas características, pelo encontro de baixos teores de cobre hepático e pela presença de quadros sintomatológico e epidemiológico sugestivos de AE (BREWER, 1983; RADOSTITS et al., 2002). 


\section{REFERÊNCIAS}

BARLOW, R.M. et al. Swayback in South-East Scotland. Journal of Comparative Pathology, v.70, p.411-427, 1960.

BREWER, B.D. Neurological disease of sheep and goats. Veterinary Clinics of North America: Large Animal Practice, v.5, n.3, p.677-699, 1983.

HOWELL, J.M.; GAWTHORNE, J.M. Copper in animal and man. Florida: CRC, 1987. V.2, 140p.

INGLIS, D.M. et al. A farm investigation into swayback in a herd of goats and the result of administration of copper needles. Veterinary Record, v.118, p.657-660, 1986.

KRUG, F.J. et al. Rapid determination of sulphate in nature waters and plant digests by continuous flow injection turbidimetry. Analyst, v.102. p.503-509, 1977.

MARQUES, A.P. et al. Mortes súbitas em bovinos associadas à carência de cobre. Pesquisa Veterinária Brasileira, v.23, n.1, p.21-32, 2003.

MAYHEW, I.G. Large animal neurology. Philadelphia: Lea \& Fiber, 1989. 380p.
McDOWEEL, L.R. Minerals in animal and human nutrition. San Diego: Academic, 1992. 524p.

OWEN, E.C. et al. Pathological and biochemical studies of an outbreak of swayback in goats. Journal of Comparative Pathology, v.75, p.241-251, 1965.

RADOSTITIS, O.M. et al. Medicina veterinária. 9.ed. Rio de Janeiro: Guanabara Koogan, 2002. 737p.

RIET-CORREIA, F. et al. Doenças de ruminantes. 2.ed. São Paulo: Varela 2001. V.2, 573p.

SAMPAIO, I.B.M. Estatística aplicada à experimentação animal. 2.ed. Belo Horizonte: FEPMUZ, 2002. 573p.

SOLAIMAN, S.G. et al. Effects of high copper supplements on performance, health, plasma copper and enzymes in gotas. Small Ruminant Research, v.41, p.127-139, 2001.

SMITH, R.D. Veterinary clinical epidemiology. Boston: Butterworth-Heinmann, 1991. 234p.

TOKARNIA, C.H. et al. Ataxia enzoótica em cordeiros na costa do Piauí. Pesquisa Agropecuária Brasileira, v.1, p.375-382, 1966.

UNDERWOOD, E.J.; SUTTLE, N.F. The mineral nutrition of livestock. 3.ed. New York: CAB International, 1999. 614p. 